\title{
Segregation Peat Fiber and Pre- Consolidation Pressure Effect on the Physical Properties of Reconstituted Peat Soil
}

\author{
Norhaliza Wahab, Kasbi Basri, Mohd Khaidir Abu Talib, Munzilah Md Rohani
}

\begin{abstract}
The preparation of the undisturbed peat sample at the site must be conducted to understand its characteristics. However, the sampling process becoming difficult due to the condition of peat soils itself. Due to the limitation in gaining undisturbed sample, a study on reconstitution sample becoming more popular in term of investigating the properties of soil that represent the real site condition. The main purpose of this paper was to investigate the physical properties of undisturbed and

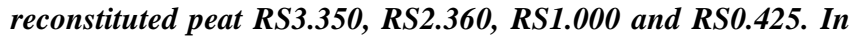
this study, the segregation of peat and expulsion water with the aids pre-consolidation pressure was applied to the reconstituted sample. The range value of the physical properties of reconstituted peat was varied from each type of peat classification which affected by the segregation fiber and pre-consolidation pressure effect method. The entire reconstituted peat samples were recons passing the opening sieve size $3.350 \mathrm{~mm}, 2.360 \mathrm{~mm}$, $1.000 \mathrm{~mm}$ and $0.425 \mathrm{~mm}$ and were subjected with the $50 \mathrm{kPa}, 80$ $\mathrm{kPa}$ and $100 \mathrm{kPa}$ pre-consolidation pressures. As a result, the natural Parit Nipah peat soil was classified as hemic peat (H5). The percentage of water content, liquid limit, organic content and fiber content for the reconstituted sample is lower compared to the undisturbed peat sample; but differed from specific gravity where the percentage for the reconstituted sample was higher than the undisturbed sample. Conclusively, the segregation of peat fiber and pre-consolidation pressure methods greatly affect and change the physical properties of peat samples.
\end{abstract}

Index Term: Reconstituted; Segregation; Pre- Consolidation Pressure; Physical Properties.

\section{INTRODUCTION}

The fiber arrangement (degree of decomposition) or known as segregation fiber of peat can contribute to the issues that may affect the physical properties of peat soil. This condition can influence the physical properties results of peat since it represents the structure and engineering properties $[1,2]$. The changing of peat fiber is depends on the degree of

Revised Manuscript Received on September 22, 2019.

Norhaliza Wahab, Faculty of Civil and Environmental Engineering, Universiti Tun Hussein Onn Malaysia, Batu Pahat, Johor, 86400, Malaysia. Research Center for Soft Soil, Universiti Tun Hussein Onn Malaysia, Batu Pahat, Johor, 86400, Malaysia

Kasbi Basri, Faculty of Civil and Environmental Engineering, Universiti Tun Hussein Onn Malaysia, Batu Pahat, Johor, 86400, Malaysia. Research Center for Soft Soil, Universiti Tun Hussein Onn Malaysia, Batu Pahat, Johor, 86400, Malaysia

Mohd Khaidir Abu Talib, Faculty of Civil and Environmental Engineering, Universiti Tun Hussein Onn Malaysia, Batu Pahat, Johor, 86400, Malaysia. Research Center for Soft Soil, Universiti Tun Hussein Onn Malaysia, Batu Pahat, Johor, 86400, Malaysia. khaidir@uthm.edu.my

Munzilah Md Rohani, Faculty of Civil and Environmental Engineering, Universiti Tun Hussein Onn Malaysia, Batu Pahat, Johor, 86400, Malaysia peat decomposition, thus affecting the changing of physical properties. Known peat is formed from decomposed soil which depends on the degree of decomposition, where the arrangement of peat is different from other types of soil. In this phenomenon, highly decomposed peat is the organic material that fully decomposed; compared to the least and moderate decomposed. Furthermore, the presence of the fiber structure in the peat soil may affect the structural arrangement and segregation level of peat formation. The provided schematic diagram in Figure 1 gives an understandable description of the peat arrangement which consists of fiber and organic particles. Kogure et al. [3] had been developed the physical model of peat structure, which then elaborate by Wong et al. [4] and Johari et al. [5] in the schematic diagram as depicted in Figure 1. Based on Figure 1, it can distinguish the components of peat is divided into two major components which are organic bodies and organic spaces. In the organic bodies, it comprises the organic particles as solid and the inner voids which are filled with water. Meanwhile, in the organic spaces components, it consists of soil particles as solid and the outer voids which filled with water. The structure arrangement of peat and the decomposition level gives different results each test in determining the physical properties of the peat soil.
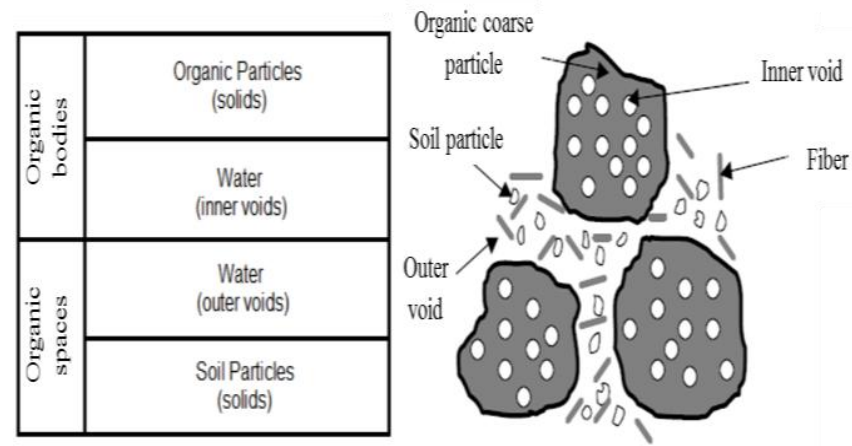

Fig 1. Schematic Diagram Peat Structure Arrangement $[3,4,5]$

Commonly, peat soil can be discovered and elaborated as soil formed from the dead wetland substance that cannot decay in a normal way due to the presence of a high water table. When the organic matter decomposed, it change into a sort of glue known as humus, which is strong enough to tie several smaller particles together, accomplishing them into larger multi- particles thus can alter the behavior of the soil [6]. 
Rahman [7] promulgated that the physical properties of peat were tremendously influenced by the porosity and the distribution of the pore size. Both of these causes related in the distribution or segregation of peat fiber. The particle size and the structure of peat were able to affect the porosity of peat which is influenced by the degree of decomposition. Thus, the increasing decomposition stage will able to decrease the size of the peat particle and also the porosity. The previous researcher has disclosed that the degree of decomposition for Parit Nipah peat is categorized as H5 (moderately decomposed peat or known as hemic peat) with the organic content between $78-93 \%$ and the fiber content in range of $40-67 \%$. Fiber content was also included and listed in the system of classifying the organic soil as the third factor to be considered. The additional factors admitted into the system have endowed better presentment and information about organic soil in Malaysia [8]. As a custom, physical properties accommodate the valuable information in determining the peat classification. The establishment of peat classification is acquired from the decomposition of fiber, formation of the organic content from vegetation, and fiber content. Based on Huat et al. [9], the types of organic soil classification can be determined from the organic and fiber content percentage as shown in Table I. The organic content in identifying the peat soil is more than $75 \%$, meanwhile the fiber content is depend on the percentage of fiber to identify the types of peat soil which is for fibric types is in the range more than $66 \%$, hemic types is in the range between $33-66 \%$ and for sapric types is less than $33 \%$. In Table II showed all the physical properties determination including degree of decomposition, sieve distribution, water content, liquid limit, specific gravity, organic content and fiber content which were applied in this study with the descriptions and significance of the tests. Each test conducted in this study based on the standard method suggested where is, for determining the degree of decomposition, the method used is Von Post determination; for sieve distribution, the method applied is wet sieving particle size distribution; water and fiber content were discovered by applying drying oven method; liquid limit obtained by applied by using fall cone method; the specific gravity determined through the small pycnometer method and organic content was recognized by applying loss on ignition (LOI) method.

Table I. Classification Based On the Organic and Fiber Content Soil Classification

\begin{tabular}{llllll}
\hline $\begin{array}{l}\text { Soil } \\
\text { Types }\end{array}$ & Description & $\begin{array}{l}\text { Sy } \\
\text { mb } \\
\text { ol }\end{array}$ & $\begin{array}{l}\text { Organic } \\
\text { Content } \\
(\boldsymbol{\%})\end{array}$ & $\begin{array}{l}\text { Fiber } \\
\text { Content } \\
(\%)\end{array}$ & $\begin{array}{l}\text { Degree of } \\
\text { Humifica } \\
\text { tion }\end{array}$ \\
\hline $\begin{array}{l}\text { Clay or } \\
\text { silt or } \\
\text { sand }\end{array}$ & $\begin{array}{l}\text { Some } \\
\text { Organic }\end{array}$ & $\mathrm{O}$ & $2-20$ & - & - \\
$\begin{array}{l}\text { Organic } \\
\text { Soil }\end{array}$ & & & & & \\
& Fibric Peat & & & $>66$ & $\mathrm{H}_{1}-\mathrm{H}_{3}$ \\
Peat & $\begin{array}{l}\text { Hemic Peat } \\
\text { Sapric Peat }\end{array}$ & $\mathrm{Pt}$ & $>75$ & $33-66$ & $\mathrm{H}_{4}-\mathrm{H}_{6}$ \\
& Sapric & & $\underline{33}$ & $\underline{\mathrm{H}}_{7}-\underline{\mathrm{H}}_{10}$ \\
\hline
\end{tabular}

Table II. Definition and significance of the test

Test Definition $\quad$ Significant

\begin{tabular}{|c|c|c|}
\hline $\begin{array}{l}\text { Degree of } \\
\text { Decomposition }\end{array}$ & $\begin{array}{l}\text { The physical } \\
\text { appearance of soil } \\
\text { was described } \\
\text { based on the Von } \\
\text { Post } \\
\text { classification. }\end{array}$ & $\begin{array}{l}\text { A detail description on } \\
\text { classification of soil } \\
\text { by refer } \mathrm{H}_{1}-\mathrm{H}_{10} \\
\text { classification of peat }\end{array}$ \\
\hline $\begin{array}{l}\text { Sieve } \\
\text { Distribution }\end{array}$ & $\begin{array}{l}\text { The list of values } \\
\text { that defines as the } \\
\text { relative amount, } \\
\text { typically by mass, } \\
\text { of particles } \\
\text { present according } \\
\text { to size. }\end{array}$ & $\begin{array}{l}\text { To verify the } \\
\text { percentage of assorted } \\
\text { sized soil particles in a } \\
\text { soil mass. The } \\
\text { determination of the } \\
\text { results allow the } \\
\text { particle size } \\
\text { distribution curve is } \\
\text { plotted }\end{array}$ \\
\hline Water Content & $\begin{array}{l}\text { The ratio of the } \\
\text { mass of water in a } \\
\text { specimen to the } \\
\text { mass of solid in } \\
\text { the specimen. }\end{array}$ & $\begin{array}{l}\text { The percentage of } \\
\text { water content can be } \\
\text { related to the } \\
\text { settlement, shear } \\
\text { strength and } \\
\text { compressibility of the } \\
\text { soil. }\end{array}$ \\
\hline
\end{tabular}

The water content at which soil

Liquid Limit passes from the plastic to the liquid state. Specify is the ratio of the weight of a designated

The limit is expressed as a percentage of the dry weight of the soil.

It is related to the degree of Specific Gravity volume of the decomposition and mass of an equal volume of water or kerosene.

The organic content is the mineral content of peat

percentage of the organic matter present in a soil. Determined typically from dry weight of fiber

Fiber Content retained on

$0.15 \mathrm{~mm}$ as a percentage of oven-dried mass

Important parameter whereby the percentage of peat and organic soils can be indistinguishable

The percentage of fiber content is used to classify the peat decomposition range.

Sieve distribution analysis is the part of physical properties which is normally identified at the early stage of testing. However, it depends on the requirement of the project. The distribution of peat can identify the types of peat from the size determination which it must be combined with the fiber content test to select the reconstitutes samples based on the types of peat (fulfill project requirement). Said and Taib [10] had given an opinion in obtaining the accurate particle size distribution analysis, wet sieving method must be conducted

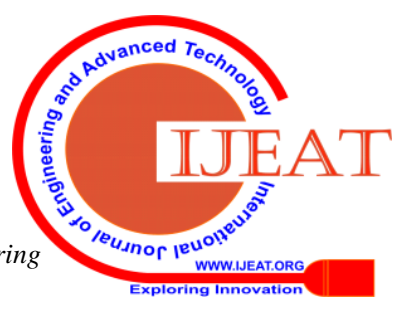


on the soil in order to break the fragment of soil particle into the smaller size. The practice of wet sieve and diffraction laser (CILAS) method for peat soil in determining soil distribution is more effective to conduct on the coarse peat [11]. Kalantari and Prasad [12] have been proved that the sizes of tropical peat commonly are between $0.006 \mathrm{~mm}$ to $5.000 \mathrm{~mm}$. Kolay and Taib [13] had mentioned the physical features is very important and useful such as colour, decomposition level, water content and organic contents and should be elaborated in a full description of peat soil. The physical features are totally influenced by the main element of peat formation such as mineral content, organic content, moisture and air. When one of these element changes, it will result in the changes in the entire physical properties of the peat soil. The water content is the most important criteria properties for peat soil. The value of water content depends on the origin, degree of decomposition and the chemical composition of peat [14]. Generally, peat has very high natural water content due to its potential for holding water capacity. The water content for fibrous peat commonly was very high. Fibrous peat dominion a considerable volume of water as its organic coarse particles are usually very loose and the organic particles full with voids and it is occupied with water. In Parit Nipah Johor, the range of water content was from 330 to $650 \%[15,16]$. In these circumstances, the high water content may affect the properties of the peat. To overcome the high water content of peat soil, the preconsolidation technique is implemented in this project. Preconsolidation is a commercial technique to drain out the redundant water content from the soil specimen. This technique is popularly applied amongst researchers in forming the reconstituted samples from slurry samples. Barnes [17] had discovered that the reconstituted sample is one of the remarkable and suitable techniques in the laboratory by element testing of repeatable and homogenous test samples. The Casagrande is a mechanical device apparatus designed in determining the liquid limit analysis. With the improvement of device technique and purposed, the cone penetrometer has superseded the Casagrande method in determination of liquid limit that still applied until now by soil researcher. Cone penetrometer method was a suitable method was relevant applied on peat soil due to the presence of peat fiber differ from other types of soil which can give difficulty during the testing process. Referred standard that explained the process of the liquid limit was specified in BS1377: Part 2: 1990. This method was applying cone penetration on the sample that placed in the cylindrical metal cup with the height $40 \mathrm{~mm}$. The moisture content of specimen that tested was determined to plot the graph cone penetration versus water content which the reading were projection at $20 \mathrm{~mm}$. The data outcomes of the liquid limit at Parit Nipah, Johor from the previous researchers is in the range 162 417\%. According to Huat et al. [9] discover the range of liquid limit for Malaysian peat soils was between $180-500 \%$. The specific gravity of peat is profoundly affected by its percentage and composition of the inorganic component. It is corresponding to the degree of mineral content and decomposition of peat Kolay and Taib [13]. A higher degree of decomposition and mineral content stipulate to the higher specific gravity. For peat soil with $75 \%$ or greater of the organic content, the specific gravity is in the range from 1.3 to 1.8 with an average of $1.5[11,18]$. Hence, the specific gravity data at Parit Nipah areas, Johor from the past researcher is in the range which is around 1.36-1.6. Huat et al. [9] had given a statement that the Malaysian peat specific gravity is in the range between 1.05- 1.9. This paper represents the reconstituted method in forming the peat sample involving the segregation of peat fiber and expulsion of excessive water through pre- consolidation pressure. On the other hand, this study had developed and expanded an understanding on the physical properties of the peat soil.

\section{EXPERIMENTAL PROGRAM}

The experimental program in this section is related with the type of peat samples and the physical properties that was conducted in this study.

\section{A. Natural Peat Sample}

All the entire peat samples were taken at Parit Nipah Darat, Batu Pahat, Johor from the depth 0.3 to $1.0 \mathrm{~m}$. The samples were taken below the water table, thus it was expected that peat samples were in fully saturated condition. Peat samples were taken in disturbed and undisturbed conditions which it is were stored in the sealed tight storage. The disturbed peat samples were utilized to perform the reconstituted sampling; meanwhile, the undisturbed peat samples were used directly to determine the physical properties. The undisturbed peat samples were extruded from the ground by using PVC pipes with the measuring $50 \mathrm{~mm}$ diameter and $100 \mathrm{~mm}$ height. Both side surfaces of PVC were laid on with the melted wax and wrapped with the aluminum foil and plastic film to avoid loss of natural water content and others nature. All the natural peat samples were transferred to the laboratory to conducting physical test analysis.

\section{B. Reconstituted Sampling Method}

The preparation of reconstituted peat samples involved wet sieving method and slurry consolidation method (preconsolidation pressure). The natural peat samples were allowed to mix with water and were sieved passing through sieve apertures $3.350 \mathrm{~mm}, 2.360 \mathrm{~mm}, 1.000 \mathrm{~mm}$ and 0.425 $\mathrm{mm}$ to obtained the homogeneous slurry paste reconstituted peat sample as shown in Figure 2. The peat soil was undergoing the wet sieving process to separate the presence of the larger fragment such as wood, leaves, organic content like an animal shell that was decay. Peat soil samples that passing through sieve opening which later on were stored in a plastic box to let specimens undergoes sedimentation. After a while, about one to two weeks, the peat sediment in the bottom of storage was collected to transfer into the remolded sampler. The selected opening sieved sized was acquire based on the maximum particle size passing sieve distribution as shown in Figure 6. 


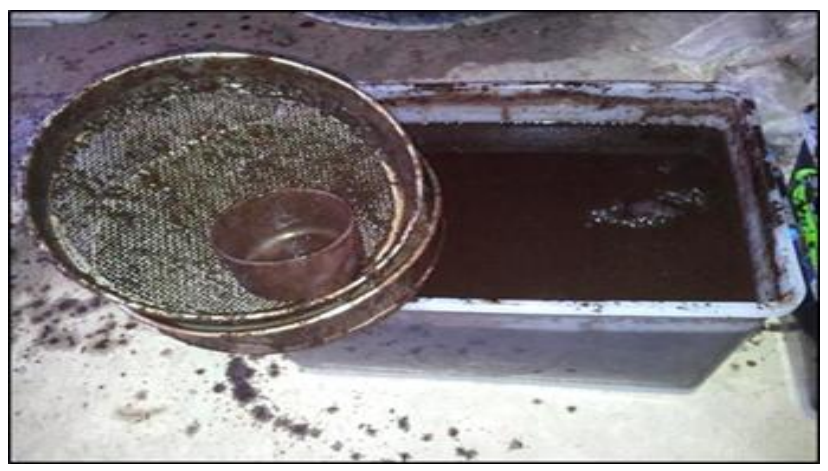

Fig 2. Segregation Peat Sizes Through Wet Sieving Method

After the wet sieving was done, the peat samples were compressed with large strain consolidation test equipment to expel the water from the slurry sample in specific measuring $120 \mathrm{~mm}$ in diameter and $400 \mathrm{~mm}$ in height of cylindrical tubes as shown in Figure 3. The porous stone was placed at the upper and bottom plates of the mould sampler to allow the water to flow through it. Samples were placed into remolded sampler equipment under initial consolidation pressure of 50 $\mathrm{kPa}, 80 \mathrm{kPa}$ and $100 \mathrm{kPa}$. Based on the graph pattern, the remolded sample with the high pre-consolidation pressure will fast settle compared to the low pre-consolidation pressure. The reconstituted peat sample assumed completed when there is no more water drained out and the settlement readings recorded flow from the bottom tube is constant as shown in the settlement versus cumulative time graph circle with red line as shown in Figure 4. After the metal load and the component of remolded sampler were dismantled, the reconstituted peat samples formed was then collected to diagnose the physical properties analysis.

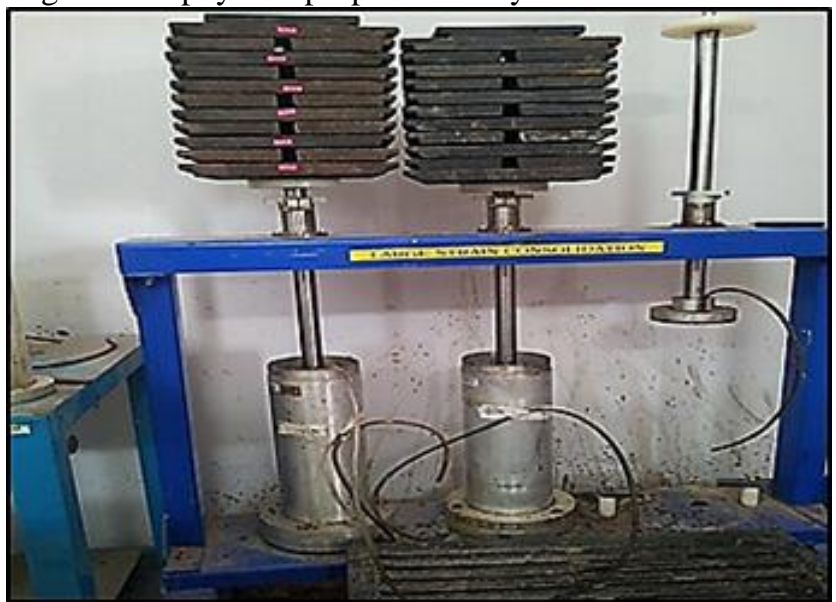

Fig 3.Pre- Consolidated Reconstituted Peat Method

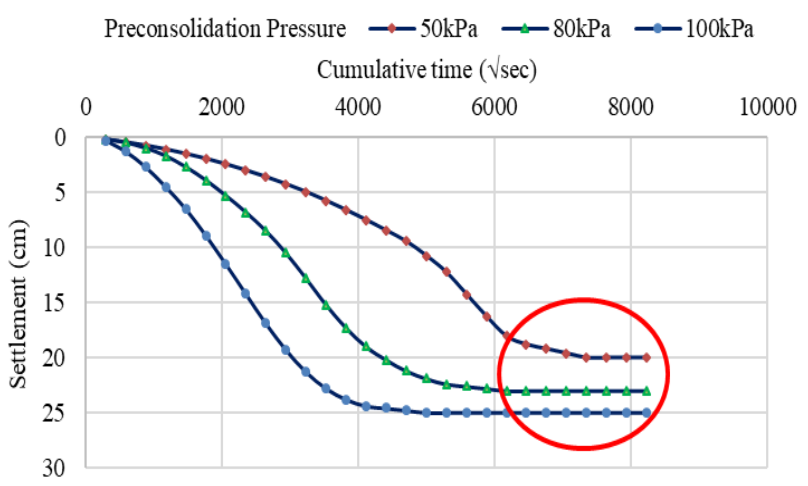

Fig 4. Slurry Consolidation Graph

\section{Physical Properties of Natural and Reconstituted Peat}

Physical properties of peat soil is very important because in order to determine the properties or characteristics of peat soil before furthering the next laboratory tests. Physical properties involve in this paper were water content, liquid limit, specific gravity, organic content and fiber content, meanwhile sieve distribution were conducted to select the segregation peat fiber size for reconstituted sample to fulfill the study requirement. The water content was determined by a standard oven drying method where the sample placed in the oven for 24 hours at a controlled temperature of $105^{\circ} \mathrm{C} \pm$ $5^{\circ} \mathrm{C}$. After the samples were drying oven after 24 hours, the peat samples then were taken out and let to cooled, afterwards the sample was weighed and recorded. For liquid limit a small portion of peat soil that passing $0.425 \mathrm{~mm}$ was mixed with the distilled water until a thick homogeneous paste was formed. After that, the paste was transferred into the $55 \mathrm{~mm}$ internal diameter and $40 \mathrm{~mm}$ deep (height) of cylindrical metal cup to let the $35 \mathrm{~mm}$ height of stainless steel cone with an angle $30^{\circ}$ \pm 1 penetrate in the soil specimen. The water content from the homogeneous paste was determine to plot the graph of cone penetration versus water content in determining at which water content corresponding to a penetration of $20 \mathrm{~mm}$. In determining the specific gravity analysis, five specimens of soil were tested. There are about 10 grams of dried soil samples that pass $2 \mathrm{~mm}$ sieve aperture were placed in the 50 $\mathrm{ml}$ density of small pycnometer bottle and then the specimens were weighed. Kerosene was filled in the bottle and agitates in a vacuum pump to remove the air bubbles. Kerosene was carefully added into the bottle and weighed again. Finally, the cleaned empty bottle had filled with the kerosene and weighed. Kerosene was used to replace the water because of the density of peat soil was less than the density of water which was causing peat soil floating on the surface of the bottle. The density of water is $1000 \mathrm{Kg} / \mathrm{m}^{3}$ which are higher than the density of kerosene that is $810 \mathrm{Kg} / \mathrm{m}^{3}$. At the same time, kerosene was used to avoid chemical interaction between the peat samples. This method is suitable in determining the particle density of fine-grained peat utilizes a $50 \mathrm{ml}$ density pycnometer bottle. Specific gravity is useful in determining the weight- volume relationship which the ratio of the density of soil to the density of water. The organic content of the peat soil can be determined through the loss of ignition test by igniting $5 \mathrm{~g}$ of dried powdered of peat soil specimens in the crucible. The specimens were then were placed into the furnace at temperature $440{ }^{\circ} \mathrm{C}$ about 3 hours. The specimen was then were cooled down into the desiccator and weighted on the weight balance to determine its mass. The weight of the specimen before and after the ignition process was measured. The ignition proses were keep to tested in the furnace with increasing 1 hours ignition period until the mass of the specimen recorded is constant. The organic content or (Loss of Ignition) of the material had been taken as the loss in mass and was described as the percentage loss in mass when the mass of organic matter acquired as the mass of loss dried sample linearly after combustion process. An established 
guideline test method for determining the quantity of fiber content in a peat sample is necessary for determining samples classification. Fiber is a fragment or piece of plant tissue that retains a recognizable cellular structure and is large enough to be retained on a 100-mesh sieve (openings $150 \mu \mathrm{m}$ ), but not considered for fiber more larger than $20 \mathrm{~mm}$. Natural peat samples were prepared and weighed approximately 100 gram. Peat sample was then placed in the $1000 \mathrm{~mL}$ beaker and mixed with the $5 \%$ of the chemical dispersing agent called sodium hexametaphosphate $\left(\mathrm{NaPO}_{3}\right)_{6}$ which are promptly diluted with the distilled water in the beaker $500 \mathrm{~mL}$. The mixture was stirred thoroughly using electrical magnetic stirrer at $240 \mathrm{r} / \mathrm{min}$ in 10 minutes. Afterwards, the mixture subsequently poured on the $150 \mu \mathrm{m}$ opening sieve and passing with tap water until the water flow through the sieve was clear. Hydrochloric acid (HCI) was used $2 \%$ to soak the peat sample to release the carbon in the sample about 10 minutes. Later on, the peat sample poured gently with tap water again. All of the fibers were washed off from the sieve screen and place into filter paper to ensure that there were no fibers that stuck to the screen. Fibers particles on the filter paper were removed and then weighed before dried into the oven at $105^{\circ} \mathrm{C}$ until a constant mass is achieved (at least 24 hours). The mass of filter paper after dried was recorded and the percentage of fiber content was determined. All the tests were conducted according to standard procedures as listed in the British Standard Institution, BS 1377: 1990 and Annual Book of ASTM Standard.

\section{ReSUlts AND DiscusSion}

All the results and discussion of each physical test were illustrated in the graphs. The summary of each result was scheduled in Table III (Appendix) based on results obtained from the plotted graph. The author also relates the analysis of the results with the previous study to validate the data obtained.

\section{A. Parit Nipah Peat Identification}

The visual identification showed that the Parit Nipah peat was dark brown and contains a high amount of fiber such as roots, branch, trunk etc. Based on Von Post classification, Parit Nipah peat is classified as H5 which is hemic peat with moderate decomposition. The identification of Von Post takes place when peat is squeezed in the palms and about one-third of the peat is removed between the fingers as shown in Figure 5. Huat et al. [9] described that the soil with a medium degree of decomposition known as H6. In addition, Zainorabidin and Mohamad [19] and Razali et al. [20] had stated that the Parit Nipah peat soil is hemic peat because has bigger particle sizes where the sample represents $\mathrm{H} 5$ and $\mathrm{H} 6$. This condition also was identified due to the Parit Nipah area is was active agriculture areas where the local people are doing farming activities such as pineapples, oil palm, cassava and sugarcane.

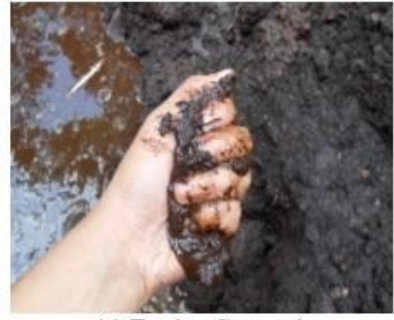

(a) During Squeezing

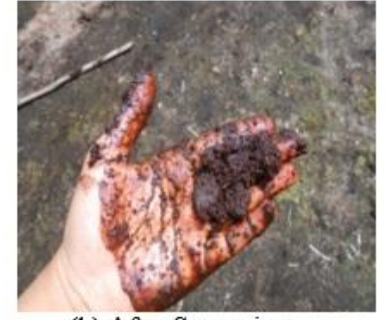

(b) After Squeezing
Fig 5. (a) and (b) Von Post Squeezing Method

\section{B. Distribution of Peat Size}

The particle size distributions of Parit Nipah peat are tabulated on a semi log scale as shown in Figure 6 with the value of D10, D30 and D60 to obtained coefficient of uniformity $(\mathrm{Cu})$ and coefficient of curvature $(\mathrm{Cc})$. From the distribution, the size of the reconstituted peat was determined by taking into account the sieve openings. The percentages of passing sieve openings are taken into account in the selection of the size of the reconstituted sample. Therefore, $3.350 \mathrm{~mm}$, $2.360 \mathrm{~mm}, 1.000 \mathrm{~mm}$ and $0.425 \mathrm{~mm}$ were selected the highest percentage of passing size for the reconstituted sample. From the semi $\log$ scale, the value of $\mathrm{Cu}$ and $\mathrm{Cc}$ were 16.739 and 0.171 respectively. Yusoff et al. [21] recorded $\mathrm{Cu}$ value for Parit Nipah peat is about 76.92 and $\mathrm{Cc}$ value is 0.0787 . Even the value of $\mathrm{Cu}$ and $\mathrm{Cc}$ is greatly different between researchers; however, peat at Parit Nipah is still behaves in various shapes and sizes due to the degree of peat to decompose.

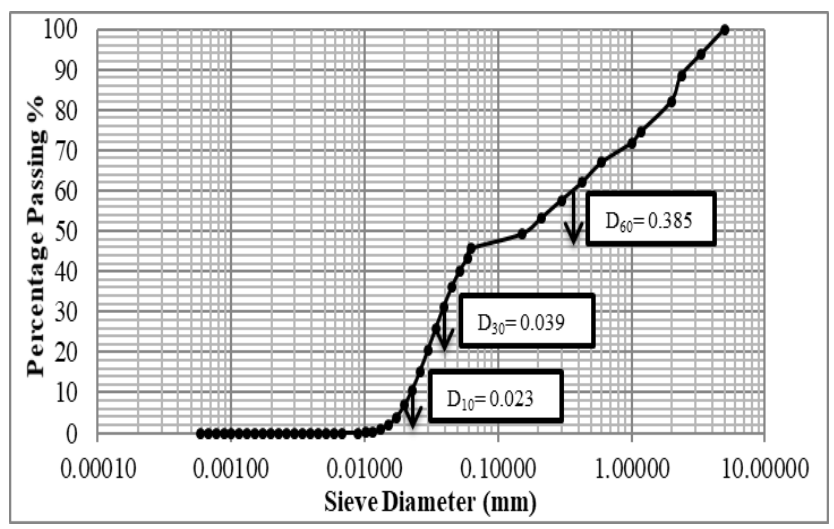

Fig 6. Particle Size Distribution of Natural Peat Sample of Parit Nipah

\section{The physical properties Relationship of segregation of peat fiber size and pre- consolidation pressure, $\sigma_{\mathrm{c}}$ -}

The data discussed in this section is related to the effect of segregation of peat fiber size and pre- consolidation pressure included with the Von Post classification.

\section{1) Water Content}

Figure 7 depict the fluctuated pattern of water content for natural peat and reconstituted peat that had been recorded. The water content of the undisturbed peat recorded was 545 $\%$. For the comparison purposed between the reconstituted peat samples, $0.425 \mathrm{~mm}$ recorded the lowest value of the water content compared to the reconstituted peat $1.000 \mathrm{~mm}$, $2.360 \mathrm{~mm}$ and $3.350 \mathrm{~mm}$ at any pre- consolidation pressure applied during the forming reconstituted sample from slurry to homogeneous paste sample. 
Meanwhile, for the comparison purpose, differences percentage of water content between undisturbed peat with reconstituted peat was decreased. The decrement of water content influences by the expulsion of water from the soil sample during slurry pre- consolidation stages. At the same time it is also caused by because the segregation effect where higher decomposition leads to lower water content. According to Johari et al. [5] the water content of the peat soil was depends on the organic matters and fiber content in the soil.

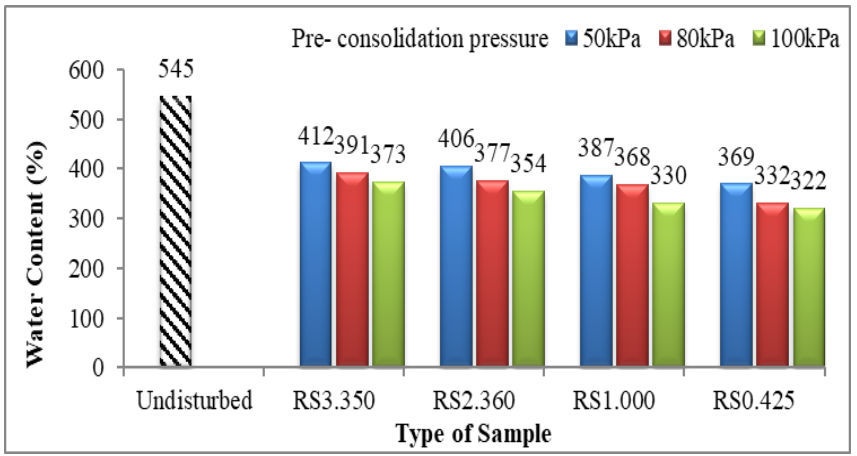

Fig 7. Water Content versus Types of Specimen

\section{2) Liquid limit}

Figure 8 depict the liquid limit graph for undisturbed peat was $370 \%$. Meanwhile, the range value of liquid limit for reconstituted peat $3.350 \mathrm{~mm}$ was $357 \%$ to $364 \%$, reconstituted peat $2.360 \mathrm{~mm}$ was $344 \%$ to $351 \%$, reconstituted peat $1.000 \mathrm{~mm}$ was $325 \%$ to $332 \%$ and reconstituted peat $0.425 \mathrm{~mm}$ was $260 \%$ to $305 \%$, depending on the value of pre- consolidation pressure respectively. However, the pattern of the percentage liquid limit between undisturbed peat with reconstituted peat $3.350 \mathrm{~mm}, 2.360 \mathrm{~mm}$, $1.000 \mathrm{~mm}$ and $0.425 \mathrm{~mm}$ were decreased. The decrement percentage of liquid limit were because of the expulsion of water from the soil sample during slurry consolidation method where higher pressure was imposed on the sample, the lower liquid limit is recorded; and larger peat size holds high water capacity, thus leads to the higher liquid limit. Rahman and Chan [14] stated that peat contains soil fabric, characterized by organic coarse particles, holds a considerable amount of water because the course particles are generally very loose, and the organic particle is hollow and largely full with water. In addition, Kolay and Taib [13] had accredited the peat that contains high fiber can contributed to high percentage of liquid limit due to high water absorption capacity.

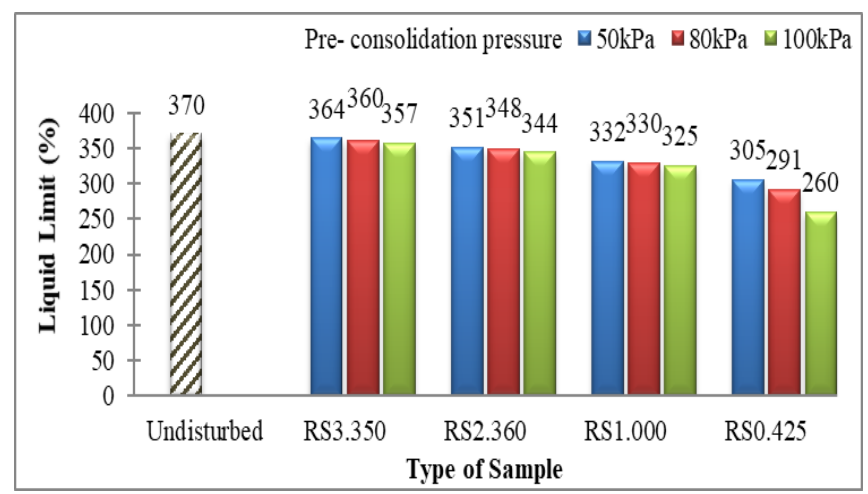

Fig 8. Liquid Limit versus Types of Specimen

\section{3) Specific gravity}

Figure 9 showed the specific gravity results recorded by undisturbed peat sample and the reconstituted peat samples. The specific gravity for undisturbed peat and reconstituted peat $3.350 \mathrm{~mm}, 2.360 \mathrm{~mm}, 1.000 \mathrm{~mm}$ and $0.425 \mathrm{~mm}$ were $1.33 \mathrm{mg} / \mathrm{m}^{3}, 1.36 \mathrm{mg} / \mathrm{m}^{3}, 1.36 \mathrm{mg} / \mathrm{m}^{3}, 1.41 \mathrm{mg} / \mathrm{m}^{3}$ and 1.49 $\mathrm{mg} / \mathrm{m}^{3}$ respectively. The specific gravity for reconstituted peat $0.425 \mathrm{~mm}$ of most decomposed peat recorded highest value compared to the least decomposed peat which was reconstituted peat $3.350 \mathrm{~mm}, 2.360 \mathrm{~mm}, 1.000 \mathrm{~mm}$ and undisturbed peat respectively. This condition was due to the degree of decomposition and mineral content of peat which is greatly affected by its composition and percentage of the inorganic component Talib and Yasufuku [11]. For difference percentage comparison purpose between the undisturbed and reconstituted peat $3.350 \mathrm{~mm}, 2.360 \mathrm{~mm}$, $1.000 \mathrm{~mm}, 0.425 \mathrm{~mm}$ were increased gradually of about 2.26 \% (RS3.350 and RS2.360), 6.02 and $12.03 \%$ (RS1.000 and RS0.425) respectively. All the results of specific gravity are in the range with previous studies that is $1.30-1.60 \mathrm{mg} / \mathrm{m}^{3}$.

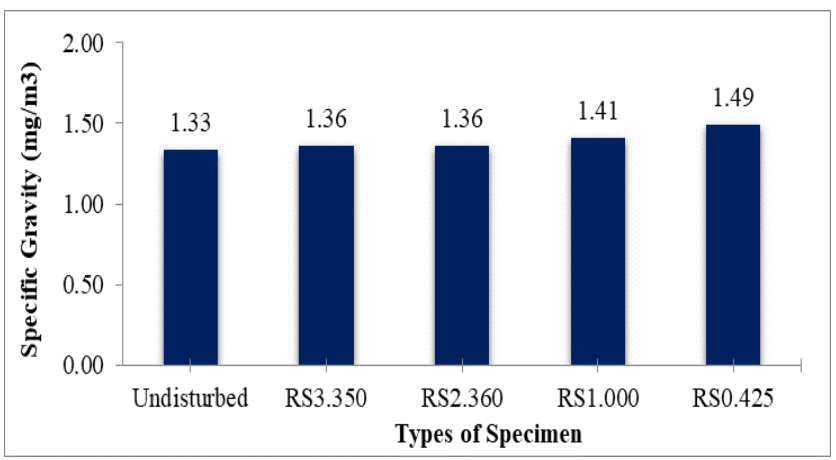

Fig 9. Specific Gravity versus Types of Specimen

\section{4) Organic content}

The organic content results for the undisturbed peat soil sample were $83 \%$ and it is in the range with the past researchers [20,22]. Meanwhile, the percentage of organic content for reconstituted peat sizes 3.350, 2.360, 1.000 and $0.425 \mathrm{~mm}$ were $80,79,77$ and $75 \%$ respectively as shown in Figure10. Thus, it can be concluded the soil distribution at Parit Nipah areas was peat soil by referring to Table 1 . However, the difference percentage of the organic content between the undisturbed peat and reconstituted peat 3.350, 2.360, 1.000 and $0.425 \mathrm{~mm}$ were decreased and was recorded as $3.61,4.82,7.32$ and $9.64 \%$ respectively. The difference percentage of organic content is due to the size of fiber gone through the segregation process during the wet sieving process which represents the degree of decomposition. The most decomposed peat had moderately lower organic content compared to the least decomposed peat [23]. 


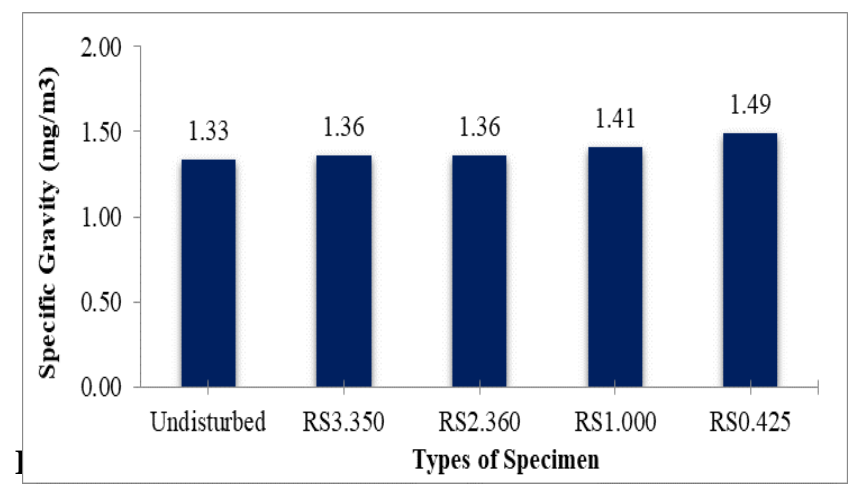

5) Fiber content

The result of fiber content in Figure 11 depicted the percentage of fiber content for undisturbed Parit Nipah peat was $60 \%$. Based on ASTM 2007, the percentage of fiber content for natural peat soil is in the range of $33-66 \%$ which is called hemic peat. The results obtained from the fiber content tests classified Parit Nipah peat as Hemic peat (H5). This statement was approved by Zainorabidin and Mohamad [19], Razali et al. [20] which reveal that Parit Nipah peat was classified as Hemic peat. The percentage of fiber content for reconstituted peat fiber sizes $3.350 \mathrm{~mm}$ and $2.360 \mathrm{~mm}$ were in the hemic peat range that were $51 \%$ and $36 \%$ respectively. However, the reconstituted peat $1.000 \mathrm{~mm}$ and $0.425 \mathrm{~mm}$ had recorded a lower percentage of fiber content compared to other reconstituted peat that was $13 \%$ respectively. The percentage of fiber content was below 33\% known as a sapric peat. The difference percentage of the fiber content between the undisturbed peat and reconstituted peat $3.350 \mathrm{~mm}$ was decreased about $15 \%$, followed by reconstituted peat 2.360 mm decreased about $40 \%$ and; reconstituted peat $1.000 \mathrm{~mm}$ and $0.425 \mathrm{~mm}$ was decreased about $78 \%$ respectively.

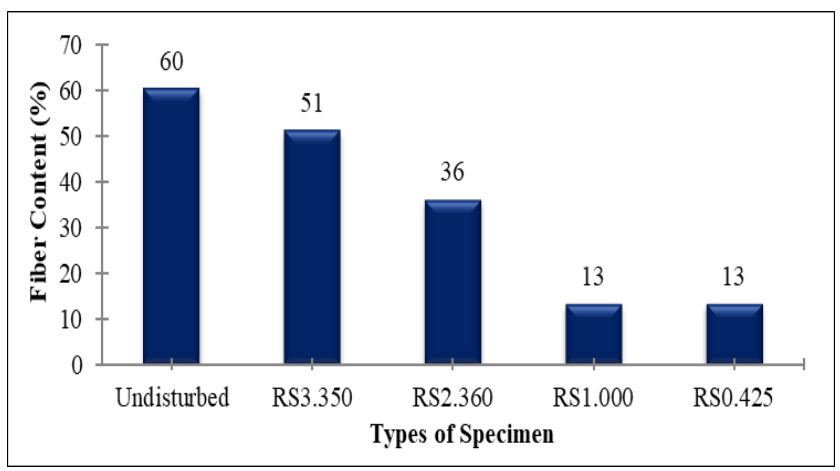

Fig 11. Fiber Content versus Types of Specimen

\section{CONCLUSION}

From the investigation, Parit Nipah peat was classified as H5. Water content for undisturbed peat was recorded (545\%) indicated that the peat soil has a high water-holding capacity due to the presence large hollow fiber. Differ with reconstituted peat samples that have a lower percentage of water content after the restructuring of the peat fiber size and pre- consolidated pressure. The liquid limit for the undisturbed and reconstituted peat was in the range with the Parit Nipah researchers which were $160-420 \%$. However, the percentage of liquid limit for the reconstituted peat from fined size to course size was increased due to the high water absorption capacity. The natural peat sample had recorded $1.33 \mathrm{mg} / \mathrm{m} 3$ of the specific gravity, simultaneously; the specific gravity for reconstituted peat sample RS3.350, RS2.360, RS1.000 and RS0.425 had recorded $1.36 \mathrm{mg} / \mathrm{m}^{3}$, $1.36 \mathrm{mg} / \mathrm{m}^{3}, 1.41 \mathrm{mg} / \mathrm{m}^{3}$ and $1.49 \mathrm{mg} / \mathrm{m}^{3}$ for each sample respectively. The specific gravity of organic soil was affected by the organic constituents such as cellulose and lignin. The peat soil is acidic with high organic and high fiber content which were common for peat soil in Johor, Malaysia. Thus, based on the fiber and organic content results, the Parit Nipah peat soil was identified as a hemic peat. For reconstituted peat, the fiber content for reconstituted peat fiber sizes 3.350 $\mathrm{mm}$ and $2.360 \mathrm{~mm}$ were classified as hemic peat and for the reconstituted peat size $1.000 \mathrm{~mm}$ and $0.425 \mathrm{~mm}$ were classified as sapric peat. The organic content of all the samples were in the range that was more than $75 \%$. To concluded, the physical properties results of reconstituted peat (represent the type of peat) is still in the range from previous researcher.

\section{ACKNOWLEDGEMENTS}

The authors kindly like to express gratitude and acknowledge to the Research Fund, UTHM, research funding grant vote (U840) TIER 1 and research funding grant vote (H011) and (H009) GPPS from Research Management Center (RMC) for giving funds in paper submission. Special gratitude also to all the staff members of Faculty of Civil and Environmental Engineering Department (FKAAS), Research Center for Soft Soil (RECESS) Universiti Tun Hussein Onn Malaysia (UTHM) for the guidance, encouragement and valuable support.

\section{REFERENCES}

[1] Yang, M. and Liu, K., 2016. Deformation behaviors of peat with influence of organic matter. SpringerPlus, 5(1), p.573.

[2] Sutejo, Y., Saggaff, A., Rahayu, W. and Hanafiah, 2017, November Physical and chemical characteristics of fibrous peat. In AIP Conference Proceedings (Vol. 1903, No. 1, p. 090006). AIP Publishing.

[3] Kogure, K., Yamaguchi, H. and Shogaki, T., 1993. Physical and pore properties of fibrous peat deposit. In 11th Southeast Asian Geotechnical Conference. Singapore (pp. 135-139).

[4] Wong, L.S., Hashim, R. and Ali, F.H., 2009. A review on hydraulic conductivity and compressibility of peat. Journal of Applied Sciences, 9(18), pp.3207-3218.

[5] Johari, N.N., Bakar, I., Razali, S.N.M. and Wahab, N., 2016, July Fiber effects on compressibility of peat. In IOP Conference Series: Materials Science and Engineering (Vol. 136, No. 1, p. 012036). IOP Publishing.

[6] Paikowsky, S., Elsayed, A. and Kurup, P.U., 2003. Engineering properties of Cranberry bog peat. In Proceedings of the 2nd International Conference on Advances in Soft Soil Engineering and Technology, Putrajaya, Malaysia (pp. 157-171).

[7] Rahman, J.A., 2015. Relationship between Decomposition Level and Induced Solidification of Peat Based on Laboratory Investigation (Doctoral dissertation, Universiti Tun Hussein Onn Malaysia).

[8] Zainorabidin, A., Wijeyesekera, D.C. and Mohd Masirin, M.I., 2007. Comparative study of British and Malaysian peat soils pertaining to geotechnical characteristics. In Proceedings of the Sri Lankan Geotechnical Society's First International Conference on Soil and Rock Engineering.

[9] Huat, B.B., Prasad, A., Asadi, A. and Kazemian, S., 2014. Geotechnics of organic soils and peat. CRC press. 
[10] Said, J.M. and Taib, S.N.L., 2009. Peat stabilization with carbide lime. Journal of Civil Engineering, Science and Technology, 1(1), pp.1-6.

[11] Talib, M.K.A. and Yasufuku, N., 2014. An overview on Japan and Malaysia peat relating to geotechnical characteristic. International Journal of Integrated Engineering, 6(1).

[12] Kalantari, B. and Prasad, A., 2014. A study of the effect of various curing techniques on the strength of stabilized peat. Transportation Geotechnics, 1(3), pp.119-128.

[13] Kolay, P.K. and Taib, S.N.L., 2018. Physical and Geotechnical Properties of Tropical Peat and Its Stabilization. Peat, p.93.

[14] Rahman, J.A. and Chan, C.M., 2014. Effect of additive to the moisture content at different decomposition level of peat. Journal of Civil Engineering Research, 4(3), pp.59-62.

[15] Mansor, S.H.B. and Zainorabidin, A.B., 2015. Stress-Strain Behavior of Parit Nipah Peat. In InCIEC 2014 (pp. 515-523). Springer, Singapore.

[16] Azhar, A.T.S., Norhaliza, W., Ismail, B., Abdullah, M.E. and Zakaria, M.N., 2016, November. Comparison of shear strength properties for undisturbed and reconstituted Parit Nipah Peat, Johor. In IOP Conf. Ser. Mater. Sci. Eng (Vol. 160, p. 12058).

[17] Barnes, D.M., 2016. Monotonic and cyclic shear response of reconstituted natural silt (Doctoral dissertation, University of British Columbia).

[18] Wahab, N. and Talib, M.K.A., 2018. The Influence of Segregation Size of Peat and Pre-Consolidation Pressure on the Effective Shear Strength Properties. In MATEC Web of Conferences (Vol. 250, p. 01013). EDP Sciences.

[19] Zainorabidin, A. and Mohamad, H.M., 2017. Engineering properties of integrated tropical peat soil in Malaysia. Electronic Journal of Geotechnical Engineering, 22, pp.457-466.

[20] Razali, S.N.M., Zainorabidin, A., Bakar, I. and Mohamad, H.M., 2018. Strength Changes in Peat-Polymer Stabilization Process; An Introduction of New Material for Peat Condition. International Journal of Integrated Engineering, 10(9).

[21] Yusoff, M., Nadia, S.A., Bakar, I., Wijeyesekera, D.C., Zainorabidin, A. and Madun, A., 2015. Comparison of geotechnical properties of laterite, kaolin and peat. In Applied Mechanics and Materials (Vol. 773, pp. 1438-1442). Trans Tech Publications.

[22] Zainorabidin, A. and Bakar, I., 2015. An Investigation of Soil Volume Changes at Four Dimensional Points of Peat Soil Sample in Parit Nipah and Pontian. In Applied Mechanics and Materials (Vol. 773, pp. 1491-1496). Trans Tech Publications.

[23] O'Kelly, B.C. and Pichan, S.P., 2013. Effects of decomposition on the compressibility of fibrous peat-A review. Geomechanics and Geoengineering, 8(4), pp.286-296.

\section{AUTHORS PROFILE}

My name is Norhaliza Wahab, affiliated with the Faculty of Civil and Environmental Engineering, Universiti Tun Hussein Onn Malaysia, Batu Pahat, Johor, 86400, Malaysia. Research Center for Soft Soil, Universiti Tun Hussein Onn Malaysia, Batu Pahat, Johor, 86400, Malaysia.

I ma Kasbi Basri, working with Faculty of Civil and Environmental Engineering, Universiti Tun Hussein Onn Malaysia, Batu Pahat, Johor, 86400, Malaysia. Research Center for Soft Soil, Universiti Tun Hussein Onn Malaysia, Batu Pahat, Johor, 86400, Malaysia

I am Mohd Khaidir Abu Talib, working with Faculty of Civil and Environmental Engineering, Universiti Tun Hussein Onn Malaysia, Batu Pahat, Johor, 86400, Malaysia. Research Center for Soft Soil, Universiti Tun Hussein Onn Malaysia, Batu Pahat, Johor, 86400, Malaysia. For more details contact me khaidir@uthm.edu.my

I am Munzilah Md Rohani, working with Faculty of Civil and Environmental Engineering, Universiti Tun Hussein Onn Malaysia, Batu Pahat, Johor, 86400, Malaysia. 